\title{
Soil-Structure Interaction Effects by Different Soil on Seismic Response of Multi-Story Building on Raft Foundation
}

\author{
H.I. Mohamad Riaz, S.M. Maheshwarappa and Dr.J.K. Dattatreya
}

\begin{abstract}
The soil flexibility effect is generally not considered in seismic design of building frames and the design is done based on results of dynamic analysis taking fixed base condition. In the present study the dynamic behaviour of building frames over raft footing under seismic forces uniting soil structure interaction is considered. For the interaction analysis of space frame, foundation and soil are considered as parts of a single compatible unit. Influence of number of parameters such as number of storey's, soil types for seismic zone-V is considered in present study. Building responses are considered for bare frame with and without accounting for soil flexibility. The responses in terms of lateral natural period and seismic base shear, lateral displacement (story drift), with and without soil flexibility is compared to evaluate the contribution of soil flexibility on building frames.
\end{abstract}

Keywords--- Soil Structure Interaction, Equivalent Soil Spring System, Natural Period, Base Shear, Raft Foundation

\section{INTRODUCTION}

$\mathrm{S}$ PECTACULAR failure of structures has been observed in every major seismic event. Gujarat earthquake of 26 January 2001 have demonstrated that the strength alone would not be sufficient for the safety of structures during the earthquake. In conventional design, buildings are generally considered to be fixed at their bases. However, if the structure is very massive and stiff, such as high-rise buildings, and the foundation is relatively soft, the motion at the base of the structure may be significantly different than the free-field surface motion. A foundation is interface between superstructure with underlying soil or rock.

Any structure subjected to seismic force during an earthquake, the waves that arrive produce motions in the structure itself. Motions depend on the structures vibrational characteristics and the structural layout or building. For the structure to response to the motion, it needs to overcome its own inertia, which result in an interaction between the structure and the soil. Such an interdependent behaviour between soil and structure regulating the overall response is referred as interaction behaviour in the present context. It is common practice that we consider the analysis of structure and foundation separately. Based on the assumption that the base of structure is fixed (i.e., assumption made that the base of the

H.I. Mohamad Riaz, M.Tech, Structural Engineering, SIT, Tumkur. E-mail:djriyaz5@gmail.com

S.M. Maheshwarappa, Associate Professor, SIT, Tumkur.

Dr.J.K. Dattatreya, Research Professor, SIT, Tumkur.

DOI:10.9756/BIJMMI.8164 foundations transfer the load by direct bearing on solid rocky stratum) load distributing within the building frames are calculated. There is no doubt that, this assumption is commonly applicable if the superstructure is much more flexible than the underlying soil stratum upon which the foundation rest. The overall stiffness of the structural systems may be decreased due to soil flexibility and hence may increase in natural period of system. Such increase in lateral natural period may considerably varies the response of building frames under the earthquake forces. For this, the present study has been carried out for dynamic response of building frames resting over raft foundation considering soil flexibility with that of a fixed base under the influence of various parameters.

If the reverse is true i.e., assuming that the structure is more stiffer than the soil medium, then the response of structure can be significantly exercised by the flexibility of soil. By the analysis of structure with fixed base condition proves to be lower estimation of certain response quantities as highlighted in few earlier researches.

\section{STRUCTURAL IDEALIZATION}

To analyse the dynamic behaviour while considering the effect of soil-structure interaction, building frames of 10, 20, and 30 storey have been idealized as 3D space frames using two nodded frame elements. Slabs at different storey level and the slabs of raft foundation was modelled with four nodded plate elements with consideration of adequate thickness. The storey height considered is $4 \mathrm{~m}$,length and width of each bay of all the building frames was chosen as $4 \mathrm{~m}$ and $5 \mathrm{~m}$ respectively for industrial building. The thickness of the roof slab, floor slabs was taken as $200 \mathrm{~mm}$ for the building considered.

These dimensions were arrived on the basis of the design following the respective Indian code for design of reinforced concrete structures

\section{RAFT FOUNDATION AND UNDERNEATH SOIL}

For understanding the importance of the effect of soil structure interaction on the seismic response of multi-story buildings, this study's attention focuses on evaluating the seismic response of reinforced concrete multi-story buildings on raft foundation with varying raft thickness which is derived on the basis of punching shear and flexure check. The underneath soil is modelled by Winkler spring approach with equivalent static stiffness based on soil properties i.e., medium and soft soil. 
Expressions for spring stiffness have been presented in Table 1 . The study primarily attempts to see the effect of soilstructure interaction on buildings resting on different types of non-cohesive soil, viz., soft, and dense. To obtain the values of the stiffness of the springs for these varieties of soil, values of shear modulus $(\mathrm{G})$ of soil have been estimated using the shear wave velocity. The other details of different soil parameters are tabulated in Table 3

Table 1: Stiffness of Equivalent Soil Springs

\begin{tabular}{|l|l|}
\hline Degrees of freedom & Stiffness of equivalent soil spring \\
\hline Vertical & {$[2 \mathrm{GL} /(1-\mathrm{v})]\left(0.73+1.54 \chi^{0.75}\right)$ with $\chi=\mathrm{A}_{\mathrm{b}} / 4 \mathrm{~L}^{2}$} \\
\hline Horizontal (lateral direction) & {$[2 \mathrm{GL} /(2-\mathrm{v})]\left(2+2.50 \chi^{0.85}\right)$ with $\chi=\mathrm{A}_{\mathrm{b}} / 4 \mathrm{~L}^{2}$} \\
\hline Horizontal (longitudinal direction) & {$[2 \mathrm{GL} /(2-\mathrm{v})]\left(2+2.50 \chi^{0.85}\right)-[0.2 /(0.75-\mathrm{v})] \mathrm{GL}[1-(\mathrm{B} / \mathrm{L})]$} \\
\hline
\end{tabular}

Where, $\mathrm{Ab}-$ Area of the foundation considered, $\mathrm{B}$ and $\mathrm{L}-$ Half-width and half-length of a rectangular foundation, respectively. The dimensions of reinforced concrete is as follows
Table 2: Section Size

\begin{tabular}{|l|l|l|}
\hline Section & Columns & Beams \\
\hline 10 Storey & $450 \times 450$ & $230 \times 450$ \\
\hline 20 Storey & $600 \times 600$ & $230 \times 550$ \\
\hline 30 Storey & $750 \times 750$ & $230 \times 700$ \\
\hline
\end{tabular}

Table 3: Details of Soil Parameters

\begin{tabular}{|l|l|l|l|l|l|l|}
\hline $\begin{array}{l}\text { Soil profile } \\
\text { type }\end{array}$ & Description & $\begin{array}{l}\text { Shear wave velocity } \\
V_{s}(\mathrm{~m} / \mathrm{sec})\end{array}$ & $\begin{array}{l}\text { SPT } \\
\text { value }\end{array}$ & $\begin{array}{l}\text { Mass density } \\
\rho\left(\mathrm{kN} / \mathrm{m}^{3}\right)\end{array}$ & $\begin{array}{l}\text { Shear modulus } \\
\mathrm{G}\left(\mathrm{kN} / \mathrm{m}^{2}\right)\end{array}$ & $\begin{array}{l}\text { Poisson's ratio } \\
(\mathrm{v})\end{array}$ \\
\hline SC & Dense soil & 600 & $>50$ & 20 & $7.34 \times 10^{5}$ & 0.3 \\
\hline SE & Soft soil & 150 & $<15$ & 16 & $3.67 \times 10^{4}$ & 0.4 \\
\hline
\end{tabular}

\section{MODEl \&ANALYSIS MethoD}

Seismic analysis for computing base shear of building frames accounting for the effect of soil-structure interaction was carried out with the help of the design spectrum provided in IS: 1893-2002 for a critical damping of 5\% considering fixed base condition and also the effect of soil-flexibility.

The effect of soil-flexibility contributes to the variations in lateral natural period, base shear and stress resultants in the structure and raft foundation. The change in the base shear has been computed by combining the contributions of all the possible lateral modes by square root of the sum of the squares (SRSS) method for building with fixed base condition and by incorporating the effect of soil flexibility. When the modes are close-spaced the CQC method is used to obtain the contribution of the modes.

In the present study, base shear of frame-shear wall building for fixed base and also for flexible base condition was arrived as per the provisions of Indian Earthquake Code by applying seismic zone factor 0.36 for very severe seismic intensity, Response reduction factor 5.0 for Special momentresisting frame and importance factor 1.0 for general residential building frames

Building is modelled using ETABS 2015. Beams are modelled as two nodded beam elements with six DOF at each node. Raft is modelled using shell element. Equivalent static analysis and Dynamic analysis is performed on models. Based on analysis result parameters such as story displacement, column forces, the time period is compared with respect to mode shape are compared for each model. Following the model have been considered
Case II: SSI model with linear springs

Case III: SSI model with two springs

\section{RESULTS AND DISCUSSION}

\section{A. Lateral Natural Period}

Fundamental natural period are plotted for the three types of models and frame type 10 storey,20 story and 30 stories

Table 4: Natural Period

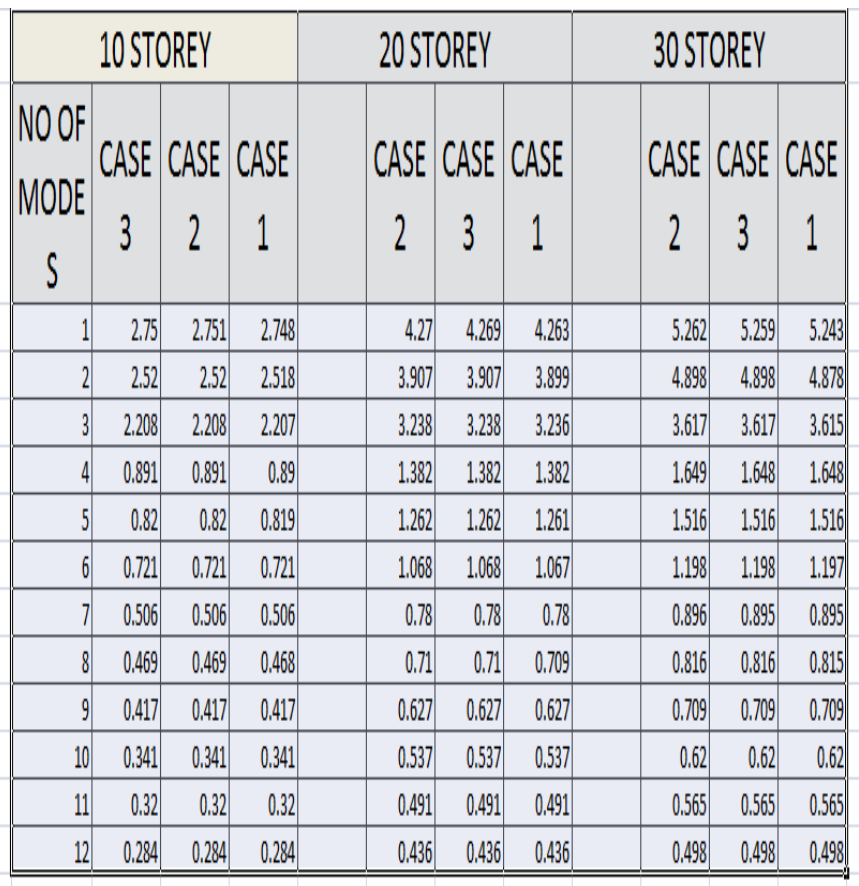

Case I: fixed support at base. 


\section{B. Maximum Storey Displacement}

Maximum storey displacement values are taken for static analysis considering 3 cases as mentioned above in $\mathrm{x}$ direction

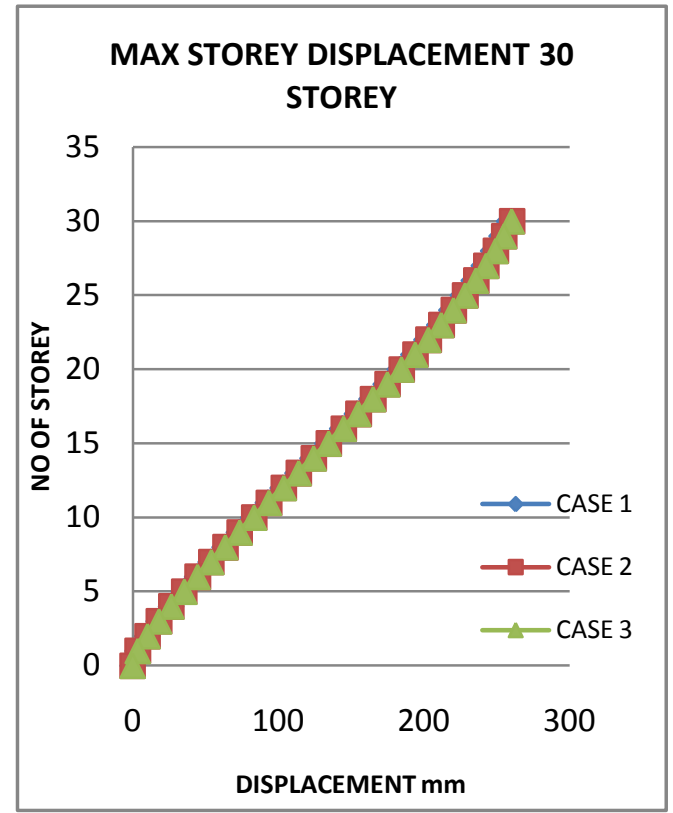

Figure 1: Max Storey Displacement 30 Storey

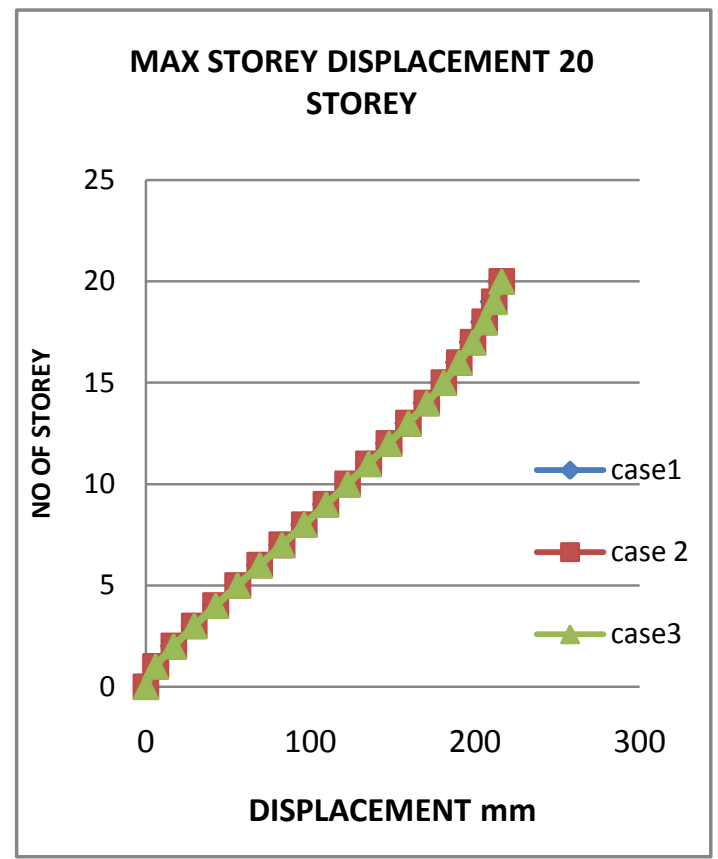

Figure 2: Max Storey Displacement 20 Storey

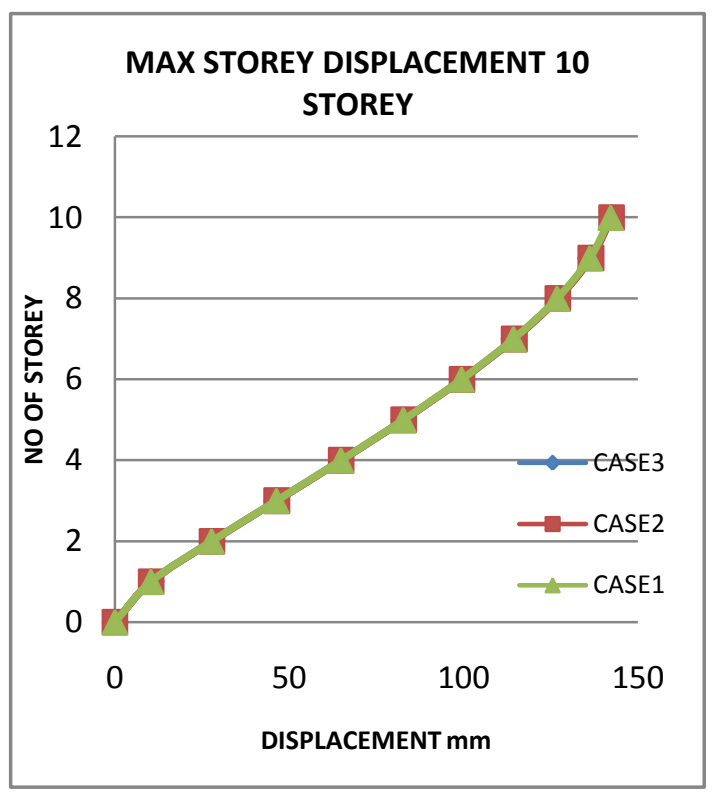

Figure 3: Max Storey Displacement 10 Storey

\section{CONCLUSION}

The study leads to the following broad conclusions:

1) Fundamental natural period: The fundamental natural period of a specific structure considering interaction is more than that of non-interaction investigation furthermore it increments with increase in number of stories fundamental natural period increments.

2) Maximum storey displacement: Displacement is more in case of soil structure interaction models.

\section{REFERENCES}

[1] J.E. Bowles, "Foundation Analysis and Design", 5 $5^{\text {th }}$ Edition, Mc Graw-Hill International Editions, Civil Engineering Series, New York, 1996.

[2] A. Chandrashekar, B.R. Jayalakshm, and K. Venkataramana, "Dynamic soil-structure interaction effects on multi storied RCC frames", Proceedings of International Conference on Advance to structural dynamics and its application, ICASDA, Pp. 454-467, 2005.

[3] IS: 1893(part 1): 2002, "Criteria for Earthquake Resistant Design of Structures", part 1-General provisions and buildings, fifth revision, Bureau of Indian Standards, New Delhi, India.

[4] IS: 456-2000, "Code of Practice for Plain and Reinforced Concrete", Bureau of Indian Standards, New Delhi, India.

[5] S.V. Jisha, B.R. Jayalekshmi and R. Shivashankar, "Contact pressure distribution under raft foundation of tall reinforced concrete industrial chimneys due to dynamic soil structure interaction", ISET golden jubilee symposium, Paper No. C003, 2012. 